Research Article

\title{
Experimental Study of Sand Distribution among Perforation Clusters in Horizontal Wellbore of Shale Gas Reservoir
}

\author{
Ting Li, ${ }^{1,2,3}$ Yongsheng Tan $\mathbb{D}^{4,5}{ }^{4,5}$ Faraj A. Ahmad, ${ }^{3}$ and Jun Zhao ${ }^{6}$ \\ ${ }^{1}$ Petroleum Engineering College, Yangtze University, Wuhan 430100, China \\ ${ }^{2}$ State Key Laboratory of Petroleum Resources and Prospecting, China University of Petroleum, Beijing 102249, China \\ ${ }^{3}$ Petroleum Engineering Department, Colorado School of Mines, Golden, CO 80401, USA \\ ${ }^{4}$ State Key Laboratory of Geomechanics and Geotechnical Engineering, Institute of Rock and Soil Mechanics, \\ Chinese Academy of Sciences, Hubei 430071, China \\ ${ }^{5}$ University of Chinese Academy of Sciences, Beijing 100049, China \\ ${ }^{6}$ China United Coalbed Methane Corporation, Ltd., Beijing 100011, China
}

Correspondence should be addressed to Yongsheng Tan; tanyongsheng2012@163.com

Received 27 December 2019; Revised 24 June 2020; Accepted 29 June 2020; Published 25 July 2020

Academic Editor: Fateme Razeai

Copyright (c) 2020 Ting Li et al. This is an open access article distributed under the Creative Commons Attribution License, which permits unrestricted use, distribution, and reproduction in any medium, provided the original work is properly cited.

\begin{abstract}
Multistage horizontal fracturing is the key technique in developing shale gas reservoirs. In each stage, several perforation clusters will be placed to create complex fractures, and the parameters of perforation clusters are almost the same, so the production from each perforation cluster should be similar. However, in fact, production from each perforation cluster is different vastly. If the characteristics of the shale gas reservoir where the horizontal wellbore oriented through are similar, the cause that resulted in production difference may be uneven proppant distribution among perforation clusters. In order to investigate proppant distribution through perforation clusters, the theory about proppant settling along horizontal lateral is analyzed, which can provide a proper pumping rate for future experiments. Then, an experimental model to simulate horizontal lateral and perforated clusters is designed. Fresh water was pumped to transport proppant flowing into different clusters, the volume of water and proppant through each cluster was qualified. Some parameters, such as proppant concentration, sizes, flow rate, and perforation parameters, are changed in lab tests; the simulation results will be helpful in understanding the phenomenon of uneven proppant distribution in perforation clusters. There are some conclusions from the experimental results. First, proppant settling at different positions along horizontal lateral is different when the slurry is mixed by proppant and water is pumped at different rates. Meanwhile, proppants concentration also has an influence on proppants settling. The settling of proppants will impact proppants distribution among perforation clusters. Second, at a low pumping rate, uneven proppants distribution was observed mostly. When the pumping rate was increased, the phenomenon of uneven proppants distribution was decreasing. Thus, the pumping rate is the main influential factor. Third, uneven proppants distribution can be improved or even avoided by adjusting perforation parameters, such as perforation numbers and diameter.
\end{abstract}

\section{Introduction}

Multistage fracturing of horizontal wells has become the major method to produce oil and gas from low permeability reservoirs, especially from shale gas reservoirs [1-5]. Along with the development of shale gas, this technology is becoming more mature. Routinely, more than three clusters are perforated in each fracturing stage, and the horizontal lateral section is fractured stage by stage from toe to heel of the horizontal wellbore. The stages and perforation clusters are placed evenly in a horizontal wellbore, but, the rate of gas produced from each stage is different significantly, and recent studies have demonstrated that one in four perforation clusters is not producing actually, and this is almost a common phenomenon in shale gas plays [6-11].

A study taken by Warpinski proved that fracture area with low proppants concentration has a negative impact on gas production, and proppant distribution in shale 
reservoirs will be critical for gas production [12]. Production logs from 100 horizontal shale wells in multiple basins were analyzed and showed that $2 / 3$ of gas production came from only $1 / 3$ of perforation clusters. Therefore, production was highly variable along the length of the wellbore. Almost $1 / 3$ of all perforation clusters were not contributing to shale gas production [13]. Perforation clusters not contributing to production could be caused by ineffective perforating techniques in many cases. A study conducted by Daneshy indicated fluid distribution uniformly into each perforation cluster was one cause for poor proppant distribution performance. When proppants carried by fracturing fluid at a high velocity are forced to change flow directions, the difference in specific gravity between proppant and fluid caused most proppant to concentrate near the lowermost perforated interval (toward toe), while the upper intervals receive mostly clean fluid without proppants [14].

The phenomenon of production difference means that the even displacement of perforation clusters and stages will not be suitable in shale gas reservoirs, and the prefracturing treatment schedule should be redesigned. The old proppant displacement method is too ideal and will result in a waste of hydraulic fracturing cost, so how to optimize the position of perforation clusters is becoming a concerned focus. Experimental tests are conducted on different types of proppant using fresh water by Faraj. It showed that parameters have a large influence on proppant settling in wellbore and distribution among different perforation clusters [15].

Bokane et al. [16] presented an extensive study and investigation of proppant transport in different perforation clusters within a single stage by using computational fluid dynamics (CFD) techniques, and these results are compared to experimental test data. Their study results indicated that proppant transport can be accurately modeled when the effects of single particle settling, density driven flow, particle velocity profiles, and slurry rheology are all considered. Crespo et al. [17] presented a first-of-its-kind large-scale investigation to study proppants distribution among separated perforations along a horizontal interval, and various liquid specific gravities, viscosities, proppant gravities, size, and slurry flow rate were investigated. Although some experiments have been conducted by the above authors, the knowledge about proppant distribution through perforation clusters is still at its infancy and needs to be investigated thoroughly.

Factors that lead to production difference in perforation clusters include both reservoir and treatment aspects. From the aspect of reservoir, the factors may be stress, gas content, geological heterogeneity, and natural fractures, etc. In view of treatment, the volume of fracturing fluid and proppant entering into those perforation clusters is different, which may influence the ultimate production severely, since the production rate depends mainly on fracture conductivity. These research results demonstrate that proppants distribution among perforated clusters should be even in order to diminish significant production differences between perforation clusters. But the research on proppants distribution among horizontal wellbore and perforation clusters was not adequate, and the basic principles were not understood in detail. Therefore, it is required to quantify proppants distribution among perforation clusters and provide valuable clues for future hydraulic fracturing designs.

This paper will present the theory of proppants deposition in the horizontal tube and perforation clusters firstly. The mass equation to control hydraulic fracturing fluid and proppants is proposed; thereby, the problem of proppants placement among perforated clusters can be solved. Next, some experimental tests are conducted to investigate the parameters which have main influences on proppants distribution among perforation clusters, and the results are discussed in theory. At last, these results will be helpful in understanding proppants distribution and production differences and provide some improvements for enhancing shale gas production.

\section{Proppant Transport in Horizontal Lateral}

In shale gas fracturing treatment, the pumping rate is normally as high as 3962 gallons/min and even will be increased to 5283 gallons/min sometimes. At this high pumping rate, proppants are difficult to deposit to accumulate as piles in the horizontal wellbore, but it is still necessary to know about proppants settling and movement conditions. In static fluid, the settling velocity of a single proppant can be predicted by Stokes' law.

Stokes' equation is not suitable for proppants transported by high-rate flowing fluid in a horizontal lateral. Many researchers have carried out a lot of work to seek for a proper equation to quantify this phenomenon. Oroskar and Turian have developed a critical deposition velocity correlation based on the energy balance required to suspend particles with energy dissipated by an appropriate fraction, $F$, of turbulent eddies present in the flow [18]. They estimated $F$ from the assumption that only those eddies possessing instantaneous velocities equal to or greater than the hindered settling velocity are effective in maintaining particles in suspension. They found $F$ to be usually very close to unity (>0.95). The value 0.95 was used for $F$ for all Newtonian and non-Newtonian critical-velocity correlations developed here. Oroskar and Turian's equation appears in the following form:

$$
\frac{v_{\mathrm{Dc}}}{\sqrt{g d_{p}(\beta-1)}}=1.85 C^{0.1536}(1-C)^{0.3564} \times\left(\frac{d_{p}}{d}\right)^{-0.378} N_{\mathrm{Re}}^{\prime 0.09} F^{0.30},
$$

where $v_{\mathrm{Dc}}$ is critical deposition velocity, at which a particle bed forms in the pipe bottom, representing the lower pump rate limit for minimum particle settling, $\mathrm{ft} / \mathrm{s} ; C$ is solid concentration, volume fraction; $d$ is inner diameter of pipe, inch; $d_{p}$ is the average particle diameter, inch; $F$ is the fraction of eddies with velocities exceeding hindered settling velocity; $\beta$ is the ratio of particle to fluid densities, $\beta=\left(\rho_{p} / \rho_{f}\right) ; \rho_{p}$ is the density of particle, pound $/ \mathrm{ft}^{3} ; \rho_{f}$ is the fluid density, pound $/ \mathrm{ft}^{3}$; $\mathrm{g}$ is the acceleration of gravity, $\mathrm{ft} / \mathrm{s}^{2}$; $N_{\mathrm{Re}}^{\prime}$ is the modified Reynolds number, $N_{\mathrm{Re}}^{\mathrm{ke}}=\left(d \rho_{f} \sqrt{g d_{p}(\beta-1)} / \mu_{a}\right) ; \mu_{a}$ is the apparent viscosity of non-Newtonian fluid, $\mu_{a}=K^{\prime}(\gamma)^{n^{\prime}-1} ; \gamma$ is the flow function, 
$\gamma=(8 \bar{v} / d)=\left(32 q / \pi d^{3}\right) ; q$ is the flow rate, $\mathrm{ft}^{3} / \mathrm{s}$; $\mathrm{K}^{\prime}$ is the consistency index, power-law-model constant; $n^{\prime}$ is the flow behavior index, power-law-model constant.

The parameters in equation (1) are included on the basis of analytical considerations; coefficient and exponent values were obtained from regression analyses of 357 critical-velocity data sets extracted from experimental investigations reported in the literature. Using turbulence theory, Davies [19] deduced a simple theoretical justification for the empirically derived exponents of equation (1).

The Oroskar-Turian correlation and others appearing in the literature were developed to describe the critical deposition velocity of Newtonian carrier fluids with various solids types, sizes, and concentrations. Subhash N. Shah and David L. Lord are not aware of any such correlations for nonNewtonian carrier fluids or the resuspension phenomena associated with Newtonian or non-Newtonian fluids, they generalized equation (1) to increase its capability to correlate critical-velocity measurements with specific operating conditions and proposed the following equation [20-22]:

$$
\frac{v_{\mathrm{Dc}}}{\sqrt{g d_{p}(\beta-1)}}=\mathrm{YC}^{0.1536}(1-C)^{0.3564} \times\left(\frac{d_{p}}{d}\right)^{-w} N_{\mathrm{Re}}^{\prime Z} F^{0.30},
$$

where $Y, w$, and $z$ are adjustable constants.

In the above equation, $Y, w$, and $z$ are adjustable constants that can be evaluated by regression analysis for particular critical-velocity data sets. $\mu_{a}$ can be substituted into $N_{\mathrm{Re}}^{\prime}$ to provide a further generalization of equation (1) for non-Newtonian fluids.

\section{Experimental Study}

3.1. Experimental Equipment. In order to investigate the distribution of proppant carried by flowing fluid in horizontal pipes, some experiments are conducted in the lab. The experimental equipment is shown in Figure 1, which consists of horizontal pipe and perforation clusters to simulate stage fracturing, a tank to mix fluid and proppant, a flowmeter, a differential pressure transducer, and a hydraulic pump. The horizontal pipe's diameter is 1.5 inches with 0.125 -inch wall thickness, and the total length is $30 \mathrm{ft}$. Along with the pipe, three perforated clusters are assembled evenly in a distance of $6 \mathrm{ft}$.

In these experimental tests, fresh water is mixed at a desired concentration in the tank equipped with a double three-bladed impeller air mixer. The slurry mixed with water and proppant is pumped into a horizontal pipe at different rates, and the weight of proppants distributed through each perforated cluster can be measured. 40/70 mesh sand, which is usually used in fracturing treatment of shale gas, was used in the experiment, and its specific gravity is 2.65 . The adjusted parameters mainly include pumping rate, perforation clusters, and proppant concentration.

3.2. Experimental Process. The experiment is aimed to investigate parameters that affect proppant distribution and how to improve proppant distribution among perforation clusters. Two groups of experiments are designed: each cluster contains 4 perforations with a density of $4 \mathrm{SPF}$ and 90-degree phasing, and clusters contain 3,4 , and 5 perforations from heel to toe separately. Meanwhile, the pumping rate is tested with three types, and sand concentration is also changed. The details of the experimental groups are listed in Table 1.

The minimal critical settling velocity is calculated by the use of equation (2) at different sand concentrations and is compared with the flow velocity at different pumping rates. It demonstrates that the designed pumping rates can satisfy the requirement of minimal critical settling velocity, so we can avoid sand settling in the pipe bottom.

\subsection{Experimental Results}

3.3.1. Each Cluster with 4 Perforations. The clusters are evenly displaced along horizontal pipe, and each cluster has 4 perforations with 90-degree phase. The perforation numbers at each cluster are shown in Figure 2. In this experimental group, the results showed that the flowing rate influences sand distribution highly, as shown in Figures 3 and 4 . As seen from Figure 3, at a lower pumping rate, such as 30 gallons/minute, $40 / 70$ mesh sand will settle down easily in the first cluster near pump outlet, and the difference will be much larger when sand concentration is increased. In the same pumping rate, the difference of proppant distribution along 3 perforation clusters is small at lower sand concentration, and the difference will be great at higher sand concentration.

Figure 4 shows that sand displacement along perforation clusters is almost different largely at a high pumping rate, but the phenomenon is reversed at a lower pumping rate. At the pumping rate of 80 gallons/minute, sand volume flowing into the third cluster is the most, and sand flowing into the first cluster will become the least. Similar to Figure 3, the uneven phenomenon of sand distribution is becoming serious when sand concentration is increased. More and more sand will settle into the third cluster. At lower sand concentration, sand distribution is almost even between perforation clusters. It may be induced that sand can be mixed evenly with water at a higher pumping rate, and sand is difficult to settle down pipe bottom. Therefore, sand will flow with water together into perforation clusters evenly. At a higher pumping rate, there may exist turbulent flow in the horizontal pipe, and sand will be transported in suspension, which is different from laminar flow. Usually, it is considered that laminar flow exists at a low pumping rate. The flowing velocity at the horizontal pipe will be much larger than the critical settling velocity of sand, so sand will be carried by fluid to flow into perforations without settling down to the pipe bottom.

No matter the pumping rate is higher or lower, sand distribution is uneven among perforation clusters with the same parameters. Comparing Figure 3 with Figure 4, it shows that sand distribution is almost the same at lower sand concentration, but the difference will become more serious after sand concentration is raised. 


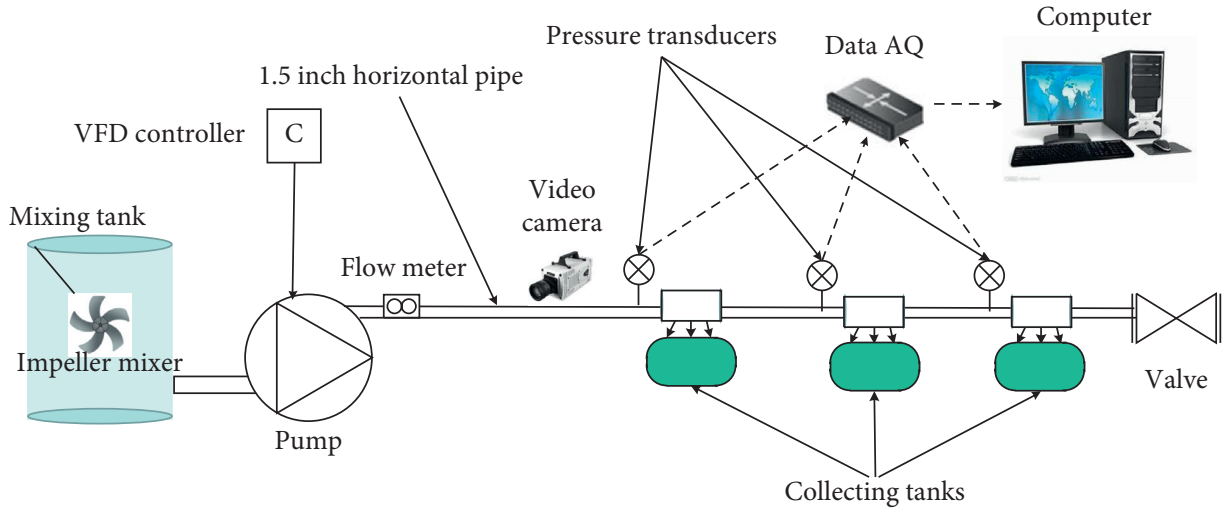

FIGURE 1: Experimental equipment and work flow (Faraj and Miskimins, 2011).

TABLE 1: Experimental groups and parameters.

\begin{tabular}{lcc}
\hline Groups & Each cluster with 4 perforations & Clusters contain 3, 4, and 5 perforations \\
\hline Pumping rate, gallon/minute & $30,50,80$ & $30,50,80$ \\
Sand concentration, pound/gallon & $0.2,0.4,0.6,0.8,1.0$ & $0.2,0.4,0.6,0.8,1.0$ \\
\hline
\end{tabular}

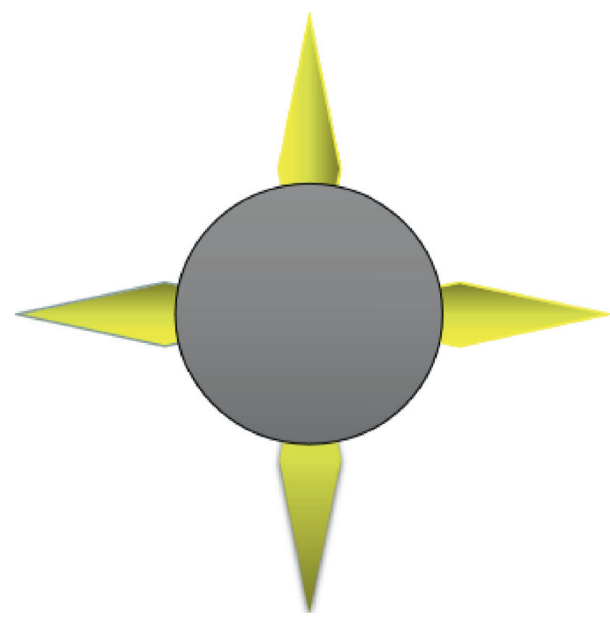

Figure 2: Perforation displaced in the pipe at 90 degrees for each cluster.

3.3.2. Clusters Contain 3, 4, and 5 Perforations. In this experimental group, the first perforation cluster near the pump has 3 perforations, the second cluster has 4 perforations, and the last cluster has 5 perforations. The diameter of each perforation is 0.25 inches, and other test conditions are the same as the first group experiment. The objective of the experiments is to study the influence of perforation numbers on sand distribution and determine whether adjustment of perforation numbers can improve sand distribution among clusters or not.

At the pumping rate of 30 gallons/minute, the perforation numbers in each cluster are listed in Figure 5, and the experimental results are shown in Figure 6. It shows that sand weight distributed among perforation clusters are almost the same, and the difference is not as large as Figure 3 in the first group experiment. It testified that adjustment of perforation numbers can balance sand distribution at each perforation cluster. This result is meaningful and presents a

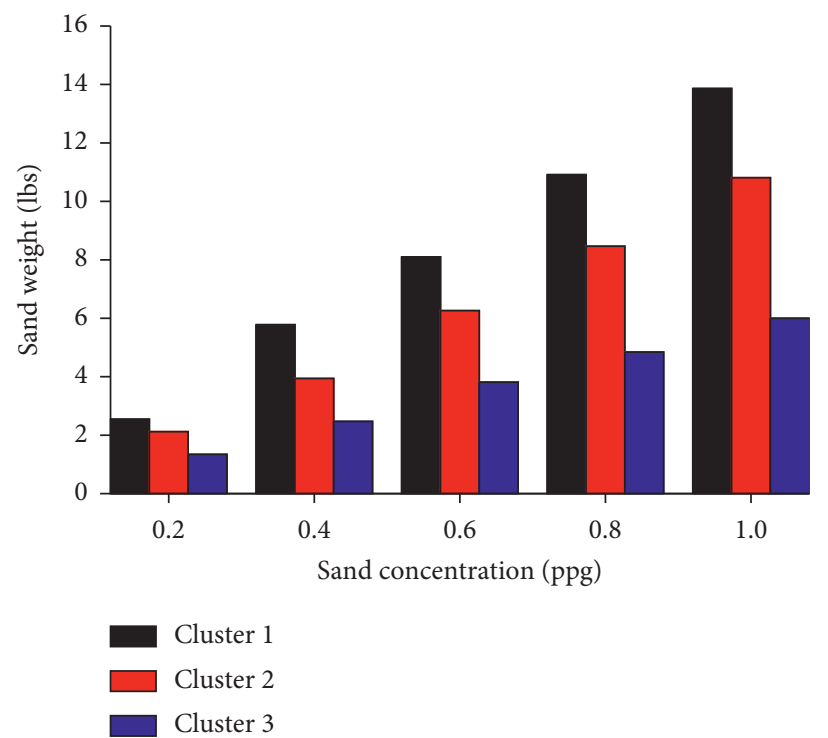

FIgURE 3: Sand distribution along perforation clusters at a pumping rate of 30 gallon/minute.

foundation for limited entry fracturing, which is promoted for multistage horizontal wellbore fracturing in the shale gas reservoir. When the pumping rate is increased, sand distribution among perforation clusters will become more uneven, so it is necessary to change other perforation parameters.

Because sand distribution becomes more uneven at a higher pump rate, the perforation numbers are changed in the next experiments. There are 5, 4, 3 perforations separately in the position of the first, second, and last perforation cluster, as shown in Figure 7. Meanwhile, other experimental parameters are not changed. The experiment is conducted at higher pump rates with different sand concentrations. The results are shown in Figure 8. Obviously, sand distribution 


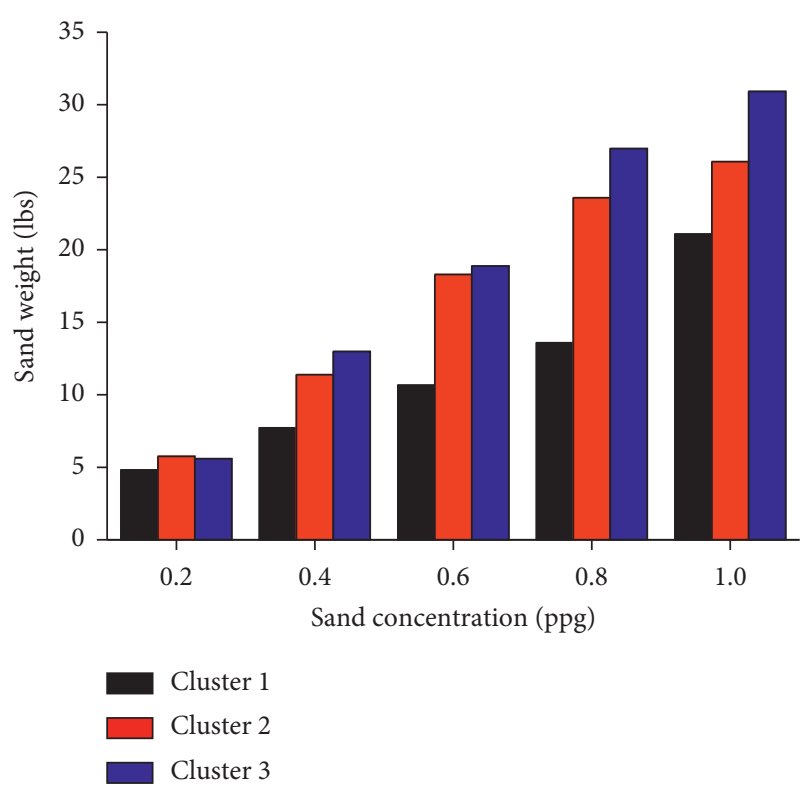

FIGURE 4: Sand distribution along perforation clusters at a pumping rate of 80 gallons/minute.

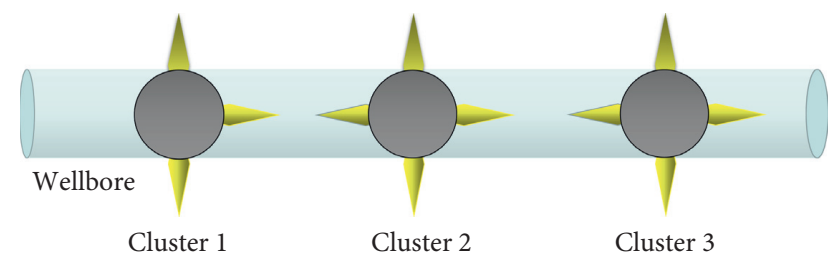

FIgURe 5: Perforation numbers in different clusters.

among perforation clusters is different a little as the sand concentration is the same. It shows that perforation numbers can also affect sand displacement among perforations, especially at a higher pumping rate.

\section{Discussion}

Sand distribution among perforation clusters will vary highly at different experimental conditions. For 40/70 mesh sand, it will create highly uneven sand distribution at the pump rate of 30 gallons/minute, and more sand will settle down at the first perforation cluster. At this condition, although flow velocity in horizontal pipe is higher than sand critical-velocity, the fluid is difficult to suspend and carry sand. Thus, a large part of the sand will settle down at the first perforation cluster near the pump. When the pumping rate is increased to 80 gallons/minute, sand distribution will become more uneven, but more and more sand will settle down at the last perforation cluster. Because flow velocity attains a higher value in the horizontal pipe, sand is difficult to settle down at the first perforation cluster. The ratio of horizontal flow velocity to vertical settling velocity is becoming higher, then the horizontal flow will dominate sand settling, and vertical settling velocity will be negligible. Meanwhile, sand resuspension after settling will occur at

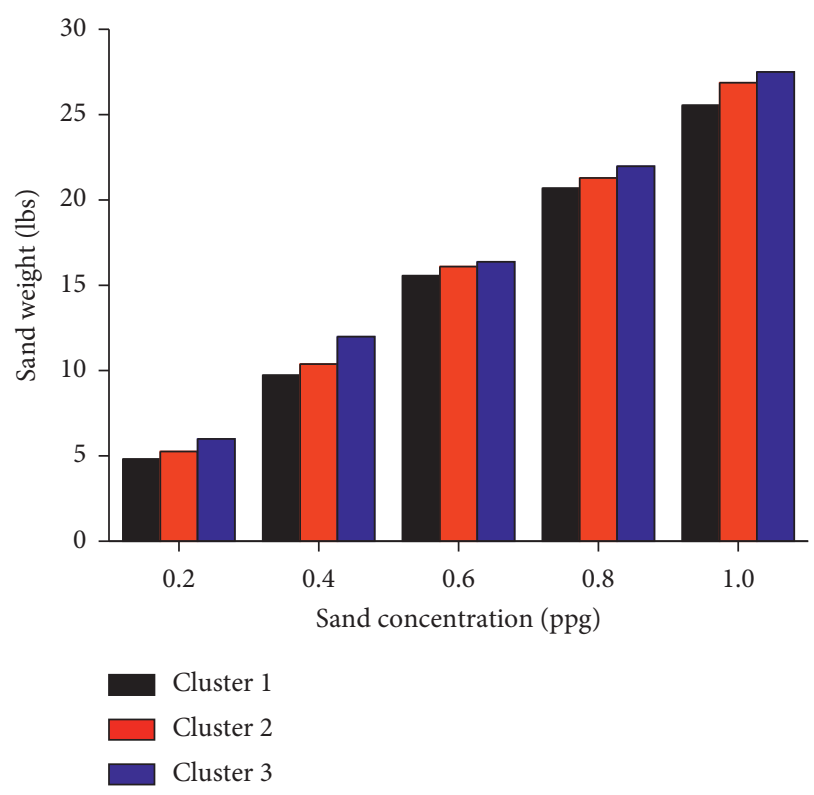

FIGURE 6: Sand distribution along perforation clusters at a pumping rate of 30 gallons/minute.

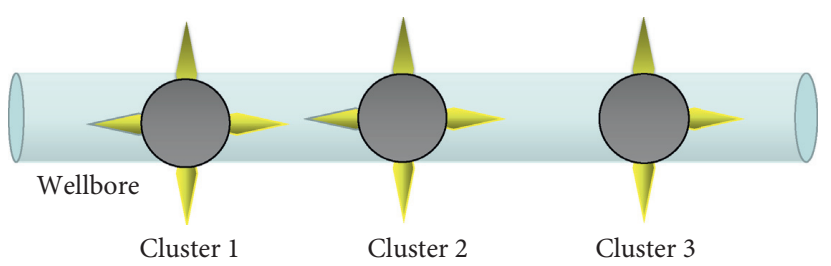

Figure 7: Perforation numbers in different clusters.

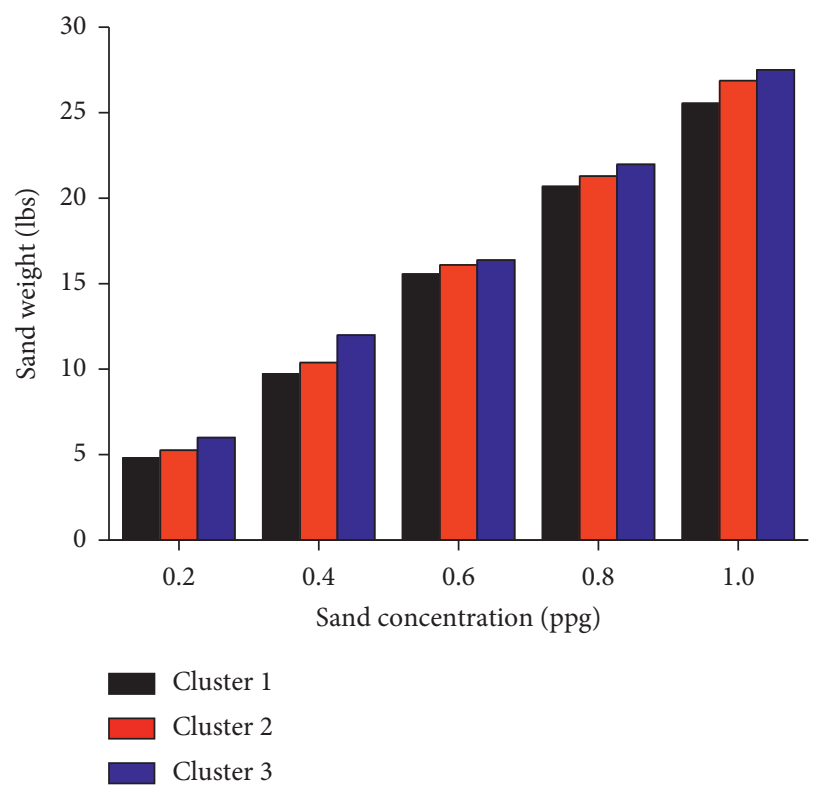

FIGURE 8: Sand distribution along perforation clusters at a pumping rate of 80 gallons/minute. 
higher flowing velocity, and sand will be flushed further by fresh water.

When perforation numbers are changed in the second group experiment, sand distribution will be even among perforation clusters at a low pumping rate of 30 gallons/ minute. Since sand easily settles down in the first cluster at 30 gallons/minute, as shown in the first group experiment, so perforation numbers are decreased to 3 , then more sand will be transported farther the first cluster. Sand settling velocity is similar in two group experiments, but sand will not enter into perforations easily in the second group experiment, and sand settling will result in the flow area decreasing, then, the flow velocity will become higher, and more sand will be flushed to other clusters at last.

At a higher pumping rate, the role of perforation numbers is not obvious, so perforation diameter is enlarged in the first cluster. Along with raising the flow rate, the flow velocity in the horizontal pipe is becoming higher, and turbulent flow will occur. In this flow status, sand will be mixed with fresh water evenly, and sand will easily flow into perforations with a larger diameter. Finally, sand can distribute evenly among perforation clusters by enlarging the perforation diameter in the first cluster and adjusting perforation numbers in other clusters.

\section{Conclusion}

From the theory of proppant transportation in the horizontal pipe and the experimental results of two groups, the following can be concluded.

In the first experimental group, 40/70 mesh sand was pumped at the rate of 30-80 gallons/minute, and sand concentration varied between 0.2 and 1.0 pounds/gallon. There are 4 perforation numbers at each cluster. Sand distribution among perforation clusters is uneven at a lower pumping rate, and the first cluster will be filled with more sand. When the pumping rate is 30 gallons/minute, more sand will accumulate at the first cluster perforation, along with the increase of sand concentration. At a higher pumping rate, more sand will enter into the last perforation cluster. At the pumping rate of 80 gallons/minute, a large portion of sand deposited down to the last perforation cluster.

In the second experimental group, 40/70 mesh sand, pumping rate, and sand concentration remained the same as the first group, but the perforation numbers and diameter are changed. The experimental results showed that uneven sand distribution can be improved by adjusting perforation numbers and diameters. At a lower pumping rate, sand can be distributed almost evenly by changing perforation numbers. Sand volume entering the first perforation cluster can be decreased by reducing perforation numbers from 5 to 3 . At a higher pumping rate, sand volume flowing into each cluster can be controlled evenly by increasing perforation diameters.

In comparison with the results of two experimental groups, it can present a good foundation for limited entry fracturing applied in shale gas, and the results will be helpful for understanding the phenomenon of uneven proppant distribution among perforation clusters.

\section{Abbreviations}

$v_{\text {Dc }}$ : $\quad$ Critical deposition velocity, at which a particle bed forms in the pipe bottom, represents the lower pump rate limit for minimum particle settling, $\mathrm{ft} / \mathrm{s}$

C: $\quad$ Solid concentration, volume fraction

$d: \quad$ Inner diameter of pipe, inch

$d_{p}: \quad$ The average particle diameter, inch

F: $\quad$ Fraction of eddies with velocities exceeding hindered settling velocity

$\beta: \quad$ Ratio of particle to fluid densities, $\beta=\left(\rho_{p} / \rho_{f}\right)$

$\rho_{p}: \quad$ Density of particle, pound $/ \mathrm{ft}^{3}$

$\rho_{f}: \quad$ Fluid density, pound $/ \mathrm{ft}^{3}$

$g: \quad$ Acceleration of gravity, $\mathrm{ft} / \mathrm{s}^{2}$

$N_{\mathrm{Re}}^{\prime}$ : $\quad$ Modified Reynolds number, $N_{\mathrm{Re}}^{\prime}=\left(d \rho_{f} \sqrt{g d_{p}(\beta-1)} / \mu_{a}\right)$

$\mu_{a}$ : Apparent viscosity of non-Newtonian fluid, $\mu_{a}=K^{\prime}(\gamma)^{n^{\prime}-1}$

$K^{\prime}$ : $\quad$ Consistency index, power-law-model constant

$n^{\prime}$ : $\quad$ Flow behavior index, power-law-model constant

$\gamma: \quad \quad$ Flow function, $\gamma=(8 \bar{v} / d)=\left(32 q / \pi d^{3}\right)$

$q$ : $\quad$ Flow rate, gallon/s

$Y, w$, and Adjustable constants.

$z$ :

\section{Data Availability}

The data used to support the findings of this study are included within the article.

\section{Conflicts of Interest}

The authors declare no conflicts of interest.

\section{Acknowledgments}

The authors would like to thank the Foundation of State Key Laboratory of Petroleum Resources and Prospecting, China University of Petroleum, Beijing (No. PRP/open-1901) and fund by China Scholarship Council with No. 201908420098. Meanwhile, the authors would also appreciate the consortium members of the Fracturing, Acidizing, Stimulation Technology (FAST) Consortium at Colorado School of Mines for supporting this study.

\section{References}

[1] G. King, "60 Years of multi-fractured vertical, deviated and horizontal wells: what have we learned?" in Proceedings of the SPE Annual Technical Conference And Exhibition, Amsterdam, The Netherlands, October 2014.

[2] T. Huang, X. Guo, and K. Wang, "Nonlinear seepage model of gas transport in multiscale shale gas reservoirs and productivity analysis of fractured well," Journal of Chemistry, vol. 2015, Article ID 349507, 10 pages, 2015.

[3] C. Dai, L. Xue, W. Wang, and X. Li, "Analysis of the influencing factors on the well performance in shale gas reservoir," Geofluids, vol. 2017, Article ID 7818346, 12 pages, 2017.

[4] H. Wang, "Hydraulic fracture propagation in naturally fractured reservoirs: complex fracture or fracture networks," 
Journal of Natural Gas Science and Engineering, vol. 68, p. 102911, 2019.

[5] T. Li and J. Wan, "Research of network fracturing method for coalbed methane reservoirs," The Open Petroleum Engineering Journal, vol. 9, no. 1, pp. 247-256, 2016.

[6] S. R. Ingram, M. Lahman, and S. Persac, "Methods improve stimulation efficiency of perforation clusters in completions," Journal of Petroleum Technology, vol. 66, no. 4, pp. 32-36, 2014.

[7] J. Deng, W. Zhu, and Q. Ma, “A new seepage model for shale gas reservoir and productivity analysis of fractured well," Fuel, vol. 124, pp. 232-240, 2014.

[8] T. Li, Y. Tan, F. Ahmad, and H. Liu, "A new method to production prediction for the shale gas reservoir," Energy Sources, Part A: Recovery, Utilization, And Environmental Effects, .

[9] Z. Chen, X. Liao, X. Zhao, X. Dou, L. Zhu, and L. Sanbo, “A finite-conductivity horizontal-well model for pressure-transient analysis in multiple-fractured horizontal wells," $S P E$ Journal, vol. 22, no. 4, pp. 1112-1122, 2017.

[10] M. Zoback and H. Arjun, Stimulating Production from Unconventional Reservoirs, Cambridge University Press, Cambridge, UK, 2019.

[11] S. Dai, C. Chen, H. Wang, Z. Fu, and D. Liu, "A semianalytical approach for production of oil from bottom water drive tight oil reservoirs with complex hydraulic fractures," Journal of Chemistry, vol. 2019, Article ID 5186831, 8 pages, 2019.

[12] N. R. Warpinski, M. J. Mayerhofer, M. C. Vincent, C. L. Cipolla, and E. P. Lolon, "Stimulating unconventional reservoirs: maximizing network growth while optimizing fracture conductivity," Journal of Canadian Petroleum Technology, vol. 48, no. 10, pp. 39-51, 2013.

[13] T. Li, Q. Yang, and B. Liu, "The mechanical analysis of network fracturing for shale gas reservoir," China Science Paper, vol. 10, no. 21, pp. 2509-2512, 2015.

[14] A. Daneshy, "Hydraulic fracturing of horizontal wells: issues and insights," in Proceedings of the Annual Technical Conference and Exhibition, The Woodlands, Texas, USA, January 2011.

[15] A. Faraj and J. Miskimins, "Proppant transport and behavior in horizontal wellbores using low viscosity fluids," in Proceedings of the Hydraulic Fracturing Technology Conference And Exhibition, Woodlands, Texas, USA, February 2019.

[16] A. Bokane, S. Jain, Y. Deshpande, and F. Crespo, "Computational fluid dynamics (CFD) study and investigation of proppant transport and distribution in multistage fractured horizontal wells," in Proceedings of the SPE Reservoir Characterisation and Simulation Conference and Exhibition, Abu Dhabi, UAE, September 2013.

[17] F. Crespo, N. Aven, J. Cortez, M. Soliman, A. Bokane, and Si. Jain, "Proppant distribution in multistage hydraulic fractured wells: a large scale inside-casing investigation," in Proceedings of the SPE Hydraulic Fracturing Technology Conference, The Woodlands, Texas, USA, February 2013.

[18] A. R. Oroskar and R. M. Turian, "The critical velocity in pipeline flow of slurries," AIChE Journal, vol. 26, no. 4, pp. 550-558, 1980.

[19] J. T. Davies, "Calculation of critical velocities to maintain solids in suspension in horizontal pipes," Chemical Engineering Science, vol. 42, no. 7, pp. 1667-1670, 1987.

[20] S. N. Shah and D. L. Lord, "Hydraulic fracturing slurry transport in horizontal pipes," SPE Drilling Engineering, vol. 5, no. 3, pp. 225-232, 1990.
[21] S. Andrei, C. Steve, and J. Sinisha, "Clustering-based optimal perforation design using well logs," in Proceedings of the SPE Eastern Regional Meeting, Morgantown, West Virginia, USA, October 2015.

[22] S. S. Yi, C.-H. Wu, and M. M. Sharma, "Proppant distribution among multiple perforation clusters in plug-and-perforate stages," SPE Production \& Operations, vol. 33, no. 4, pp. 654-665, 2018. 